\title{
Vegetative development, primary and secondary growth of the shoot system of young Terminalia superba tropical trees, in a natural environment. II. Terminal growth, lateral growth and main stem-branch growth correlations
}

\author{
E de Faÿ \\ Université de Nancy I, Laboratoire de biologie des Ligneux, BP 239, \\ 54506 Vandœuvre-lès-Nancy Cedex, France
}

(Received 22 July 1991; accepted 17 April 1992)

\begin{abstract}
Summary - Primary and secondary growths of main and lateral axes of 1-year-old Terminalia superba Engl and Diels trees, as well as some other aspects of vegetative development, were studied in a natural tropical environment and followed for a period of 6 months. During the long rainy season, primary growth of main axes was continuous, but the rates of shoot elongation and leaf emergence fluctuated rhythmically and correlatively. Shoot elongation rhythm often lagged a little behind leaf emergence rhythm. In addition, leaf development was homoblastic. Lateral shoots appeared when leaf emergence was at a maximum; consequently, they were arranged in successive tiers (pseudowhorls of branches). The apposition of sympodial units in the developing tier of the trees resulting in the typical Terminalia branching - did not depend on the existence of the main apex, but it was limited as soon as new lateral axes branched above the tier in question. From that time, the activity of branch apices and the radial growth of branch bases ceased, or at least were not detected further. Radial growth of trunks was continuous, but the growth rate of the upper parts changed in relation to the occurrence of tiers. Reiteration of the main apex in an accidentally decapitated plant was late: it occurred after the uppermost branch tier had reached a large size. These results indicate different types of growth correlation in the shoot system of young Terminalia superba trees. It is suggested that the particular growth features of this species are related to the presumably successive sink/source roles of the uppermost tier of branches for metabolites. This growth-habit was observed under favourable environmental conditions. At the end of the long dry season, it was not so obvious, since shoot growth could cease for a couple of weeks and radial growth slowed down slightly.
\end{abstract}

main stem-branch growth / radial and shoot growth / rhythmicity / Terminalia superba / tropical tree

Résumé - Développement végétatif, croissance primaire et secondaire du système caulinaire de jeunes arbres tropicaux de l'espèce Terminalia superba, dans un environnement naturel. II. Croissance terminale, croissance latérale et corrélations de croissance tige principale-branche. Les croissances primaire et secondaire des axes principaux et latéraux de Terminalia superba Engl et Diels âgés de 1 an, ainsi que quelques aspects du développement végétatif, furent étudiés dans un environnement naturel tropical et suivis sur une période de 6 mois. Durant la grande saison des pluies, la croissance primaire des tiges principales était continue, mais les 
taux d'allongement apical et d'émergence foliaire fluctuaient rythmiquement et corrélativement. Le rythme d'allongement apical était un peu en retard sur le rythme d'émergence foliaire. En plus, le développement des feuilles était homoblastique. Les rameaux latéraux apparaissaient quand l'émergence des feuilles était maximale; en conséquence, ils étaient disposés en étages successifs (pseudo-verticilles de branches). L'apposition d'unités sympodiales dans l'étage en croissance des arbresaboutissant à la ramification du type Terminalia - ne dépendait pas de l'existence de l'apex principal, mais elle était limitée dès que de nouveaux axes latéraux se ramifiaient au-dessus de l'étage de branches en question. Dès ce moment là, l'activité des apex de branche et la croissance radiale des bases de branche étaient arrêtées, ou du moins non détectées. La croissance radiale des troncs était continue, mais le taux de croissance des parties supérieures changeait en fonction de l'apparition des étages. La réitération de l'apex principal chez une plante accidentellement décapitée était tardive, elle survenait après que l'étage de branches le plus haut ait atteint une grande taille. Ces résultats attirent l'attention sur des types différents de corrélation de croissance dans le système caulinaire des jeunes arbres de l'espèce Terminalia superba. II est suggéré que les caractéristiques particulières de la croissance de cette espèce sont liées aux röles vraisemblablement successifs de zone d'appel/ source, de l'étage supérieur de branches à l'égard des métabolites. Ce mode de croissance a été mis en évidence dans des conditions d'environnement favorable. Á la fin de la grande saison sèche, il n'a pas pu être observé de façon aussi manifeste, puisque la croissance caulinaire pouvait être arrêtée pendant 1 ou 2 semaines et que la croissance radiale ralentissait légèrement.

croissance tige principale-branche / croissance radiale et apicale / rythmicité / Terminalia superba / arbre tropical

\section{INTRODUCTION}

A first paper (de Faÿ, 1992) reports that the main axis of young Terminalia superba Engl and Diels trees grown in a natural tropical environment did not have the typical features of flushing species. The 'pagoda' architecture of the species (Aubréville's model from Hallé and Oldeman, 1970) seemed to result more from branching than from a rhythmic growth of the main shoot, at least in the early stage. Trunkbranch correlations were displayed, which is the reason why this study was continued to examine the temporal aspects of the growth of young Terminalia superba trees in the same natural environment, including the lateral and radial growth of the tree.

In the present paper, shoot growth of main stems is described, ie shoot elongation, leaf types and leaf emergence, which allow us to compare this shoot growth under natural conditions with that under controlled conditions reported to be continuous at $22{ }^{\circ} \mathrm{C}$ and rhythmic at $27^{\circ} \mathrm{C}$ under photoperiods of $14 \mathrm{~h}$ and $16 \mathrm{~h}$ daylengths (Maillard et al, 1987a). Besides terminal growth, lateral growth is also described, ie the appearance of axillary shoots and dynamics of branching, as well as radial growth of both main stems and branches. In addition, one occurrence of main stem reiteration is described. The objective of this study was to improve our knowledge of growth phenomena in a young tropical tree and to obtain more details about main stem-branch growth correlations.

\section{MATERIALS AND METHODS}

The trees studied here were seedlings planted at the age of 3-4 months in a prepared plot in the Anguédédou forest, located about $30 \mathrm{~km}$ northwest of Abidjan on the Ivory Coast. Plants had a 2-m spacing within a line and more between lines. Five 1-year-old plants were followed at weekly intervals over a period of 6 months. Weeds, particularly Eupatorium odoratum, a very invasive Asteraceae, were pulled up manually around the plants, each week if neces- 
sary, so that the $5 T$ superba plants observed were growing in full sunlight without any neighbouring competition. This observation began during the long dry season (November-March), on January 8th and was continued during the long rainy season (April-Mid July), up to July 2nd. None of the young plants were deciduous during the observation period.

The height of main stems was measured with a tape measure. The newly mature leaves on these stems were tagged with a marker pen on the blade and the total number of leaves was counted, including the 1-mm long newly-formed leaves. This was possible because the developing leaves were not closed up against each other on young shoots, and the upper leaves could be moved away from the young stem easily during counting without damage. Leaf morphology was examined in order to determine the leaf types. The total number of apical buds of sympodial units, called branch buds, was counted on each branch, as well as the number of active buds exhibiting developing (green) leaves. The mean diameter of axes was measured with a calliper rule: main stems at $5 \mathrm{~cm}$ above and below each tier, and different branches at the base.

A complete set of data was collected for each of the 5 trees. The choice was made to present the different features of growth in the most vigorous tree, ie $T_{2}$. Results from trees $T_{1}, T_{3}$ and $T_{5}$ were similar. In several figures, some of them were presented together with those of $T_{2}$. Tree $\mathrm{T}_{4}$ exhibited a peculiar growth, caused by an accidental decapitation in the second month of observation. When interesting, data were shown in separate figures.

\section{RESULTS}

\section{Main shoot elongation}

The height of main stems did not increase at a constant rate for the 25 weeks of observation (fig 1). The growth of all the plants was alternately fast and slow, but there was only one short rest period. It occurred in February in all cases (at the end of the long dry season). Afterwards, the

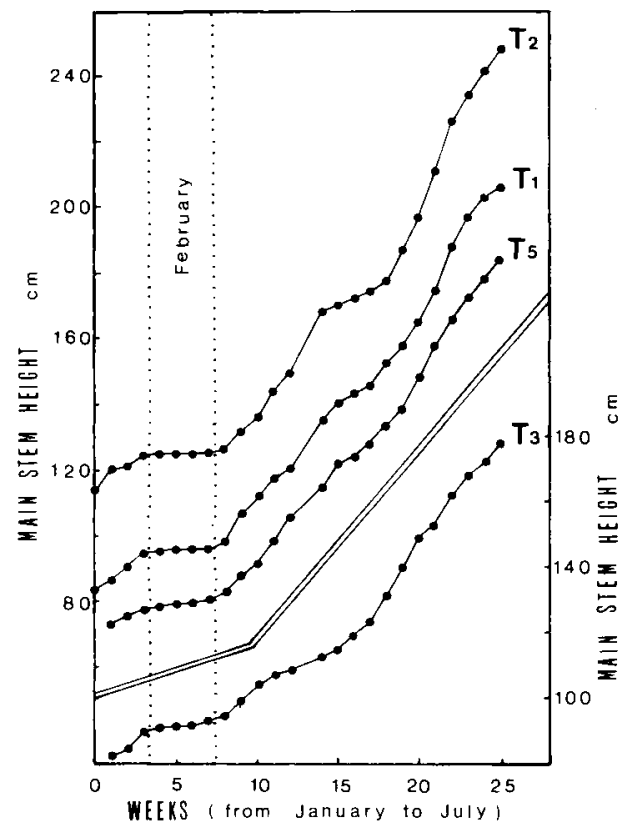

Fig 1. Height-growth of 4 young Terminalia superba trees $\left(T_{1}-T_{3}, T_{5}\right)$.

main shoot increment fluctuated asynchronously among the plants studied.

\section{Leaf emergence and leaf types on main stems}

Weekly examination of the growing points permitted the number of $1-\mathrm{mm}$ long leaf primordia that emerged per week to be calculated. This leaf emergence seemed to be continuous at first sight (fig 2). In fact, it stopped for a few weeks in February, and afterwards, the rate of leaf emergence varied from 1-6 leaves a week (fig 3). Main apices produced only foliage leaves. These leaves stopped growing for a short while in February and a sort of brownish bud was seen at the apex of the main 


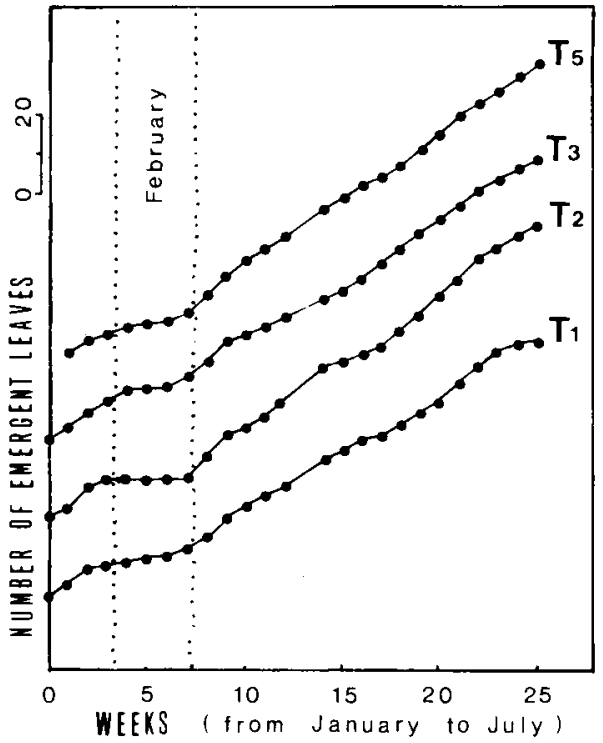

Fig 2. Evolution of the number of emergent leaves on the main stem in 4 young Terminalia superba trees $\left(T_{1}-T_{3}, T_{5}\right)$.

stems (an inactive bud surrounded by small 'arrested' leaves, covered with long yellowish hairs). At the resumption of shoot growth, a few leaves arrested in their growth fell off and short internodes were then found on main stems, indicating a period of growth rest. For the rest of the observation time, main apices were simply surrounded by the growing leaves they had produced. The light green colour of young chlorophyllous leaves distinguished the active apices clearly. At the beginning of the observations, variations in the rate of leaf production were synchronized amongst the young plants observed; but from the end of February, these fluctuations ceased to be synchronized. However, it is worth noting that all the main shoots presented as many phases of slow leaf emergence as phases of slow shoot elongation. These phases coincided with each other, although the latter often lagged a little behind the former (fig 3 ). The mean periods of leaf emergence and shoot elongation rhythms were similar to each other, being $7.3 \pm 1.5$ and $7.3 \pm 1.7$ weeks respectively among the trees observed from the end of February.

\section{Appearance of lateral branches}

The majority of axillary buds on main stems were very small and hidden between the petiole base and the stem (only a tuft of hairs was seen, indicating the top of the buds). A swelling at the axil of some young leaves, already well-separated from the apex, was the first sign of the outgrowth of a sylleptic shoot. Axillary buds expanded very close to the main apex, probably in the elongating part of the stem. Sylleptic shoots always arose on main stems during phases of rapid leaf emergence on main shoots, either at the beginning of phases of rapid main shoot elongation or at the maximum point of this elongation (fig 3). It should be noted that other sylleptic shoots, corresponding to the 2nd-4th (sometimes up to the 6th) sympodial units of the different branches of new tiers appeared at the point of maximum leaf emergence on main shoots (fig 4). Moreover, just after the exceptional rest in February, the only axillary buds that started at maximum leaf emergence on the main shoot of $T_{1}$ and. $T_{2}$ were located on sympodial units of the last-formed tier, which was then little developed (fig 4).

At the end of the observations, the 3 last-developed tiers of trees (the decapitated tree is not considered) consisted of 1-7 branches separated from each other by $1-$ 3 internodes which appeared during a period of 1-3 weeks. These tiers were separated from each other by 11-23 internodes 


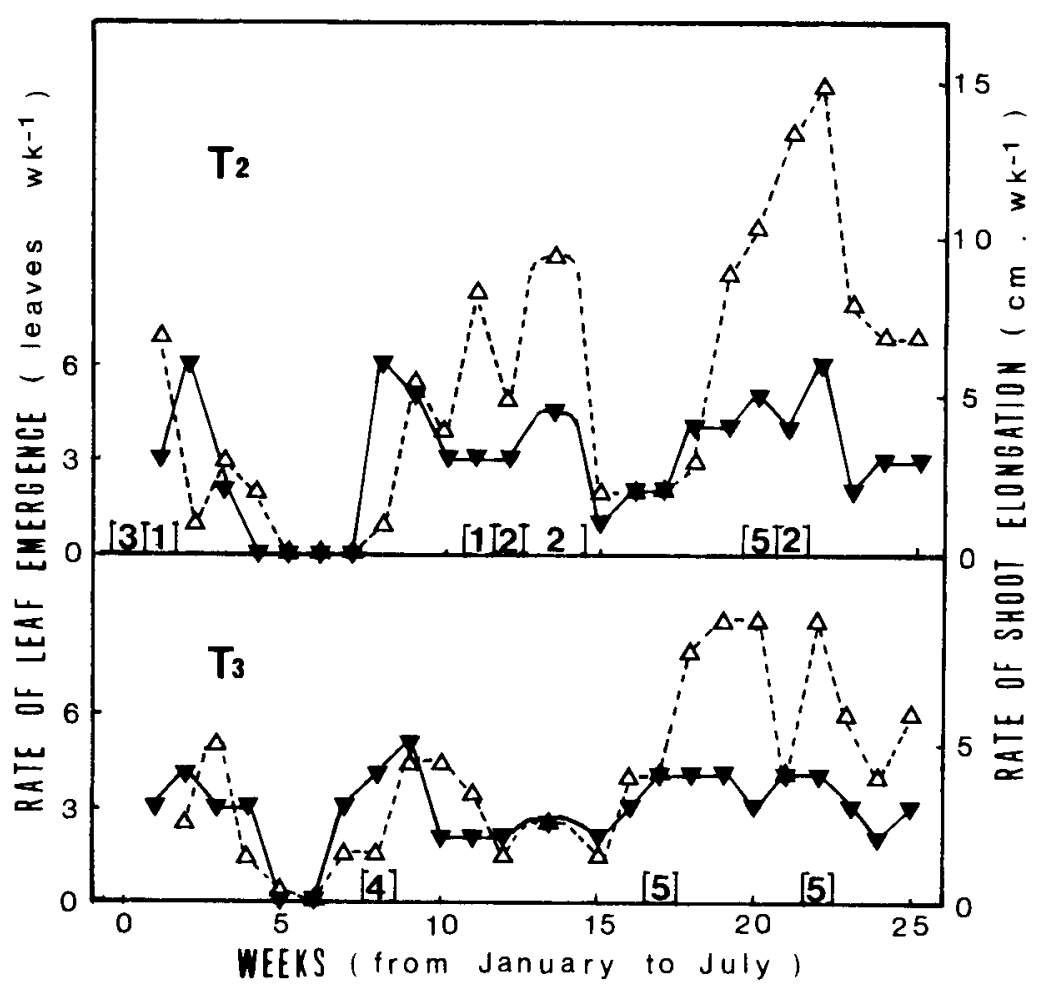

Fig 3. Leaf emergence $(\nabla-\nabla)$, shoot elongation $(\Delta-\Delta)$, appearance and number of branch buds [ ] on the main stem, in 2 young Terminalia superba trees $\left(T_{2}\right.$ and $\left.T_{3}\right)$.

which appeared over a period of 5-14 weeks.

\section{Dynamics of branching}

Since a branch develops by an apposition of sympodial units, each derived from one axillary bud by syllepsis, the size of a branch, a tier or a tree can be evaluated by the number of lateral apices (the apices of sympodial units). Because of their role in branch building, these are called branch apices or branch buds henceforth in the text. Evolution of the number of branch buds permits one to estimate lateral growth. It was clear (fig 5) that all the branches of a tier initiated at the beginning of the observation period grew slowly and those initiated later during March and after grew faster; then tiers became more frequent. However, regardless of the time of initiation, tiers still produced a few sympodial units after the appearance of other lateral axes above them.

Branch apices could be either active recognizable by the light green colour of young growing leaves - or inactive - recognizable by the brownish colour of small arrested leaves (fig 6). Branch buds were active in the uppermost tier, except some- 


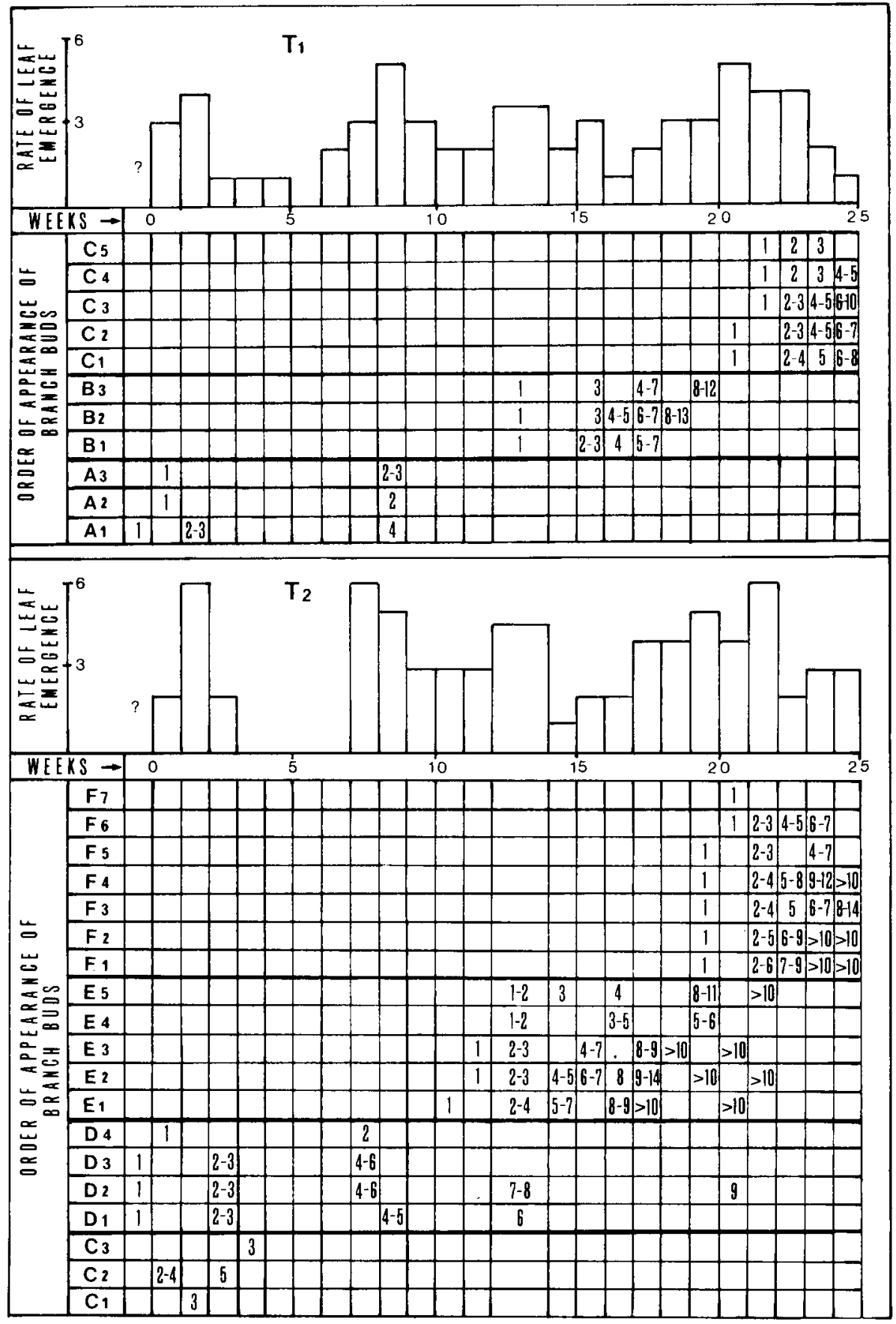


times the ones of the oldest sympodial units. Branch buds were inactive in lower tiers with some variation (figs 6,7 ). At first the number of active buds per branch increased in the new tier. After reaching a maximum, which varied with the tier order and from one branch to another, it decreased quickly to zero, at least temporarily. Several periods of activity were recorded in the tiers that were initiated at the beginning of the observation period (figs 6 , 7). Branch bud activity was relatively synchronous in a tier, but delayed between 2 tiers, especially those initiated during March and after (fig 7). As soon as a new tier began to produce some relay sympodial units, branch bud activity decreased quickly in the next upper tier and finally was no longer detected (fig 6,7). Then the new tier became the most active and when its active branch buds became numerous, new axillary shoots appeared on the main shoot above it.

Consequently, during March and after the total number of active branch buds per tree was always sizeable, even if it fluctuated (fig 8). Thus, each tree had numerous active branch buds, which were in slow vertical growth phase, and it did not stop expanding new leaves. No distinct growth periods were observed.

\section{Radial growth of trees}

Diameter of branch bases first increased rapidly before reaching a maximum; then it fluctuated slightly or sometimes decreased slowly (figs 9,10 ). Radial growth of branch bases started precociously, probably from the first weeks of branch formation, and it went on for a couple of weeks after the activity of branch buds began to decrease in these branches (fig 10). The cessation of radial growth and the beginning of branch shrinkage also coincided with the beginning of branching in a recently initiated tier (fig 9). Thus radial growth of branches lasted a little longer than their shoot growth. The oval, vertically elongated form of the transverse section of branch bases was also noted.

Radial growth of main stems was continuous for the six months of the observation period, but growth rates varied in time and in space since it changed with the occurrence of new tiers (fig 11). In the upper part of young stems (above the uppermost tier), radial growth rate was low. When a new tier appeared above the stem level considered, it increased suddenly, and then remained rather constant. Radial growth rates were almost the same on both sides of lower branch tiers. Apparently, there was no other variation in radial growth rates of the 5 trees studied that could be related to fluctuations of the main shoot growth.

However, radial growth rates of middle and lower parts of main stems varied according to the season (fig 11). Radial growth was slow at the beginning of the observation period (in February, it stopped in some cases and there was even trunk shrinkage). The speed of radial growth was increased during March and after, in the equivalent parts of main stems.

Fig 4. Association in time of the phases of rapid leaf emergence on the main stem and the appearance of branch buds relatively close to the main apex (1: on the main stem; 2-3: on first sympodial units 4,5 etc on the following ones), on different branches $\left(A_{1}-C_{5}\right.$ or $\left.C_{1}-F_{7}\right)$ of 2 young Teminalia superba plants $\left(T_{1}\right.$ and $\left.T_{2}\right)$. Rate of leave emergence is the number of new leaves per week. In branch name, alphabetical order of capitals indicates the order of appearance of branch tiers and numeral order of subscripts the order of branches within the tier. 


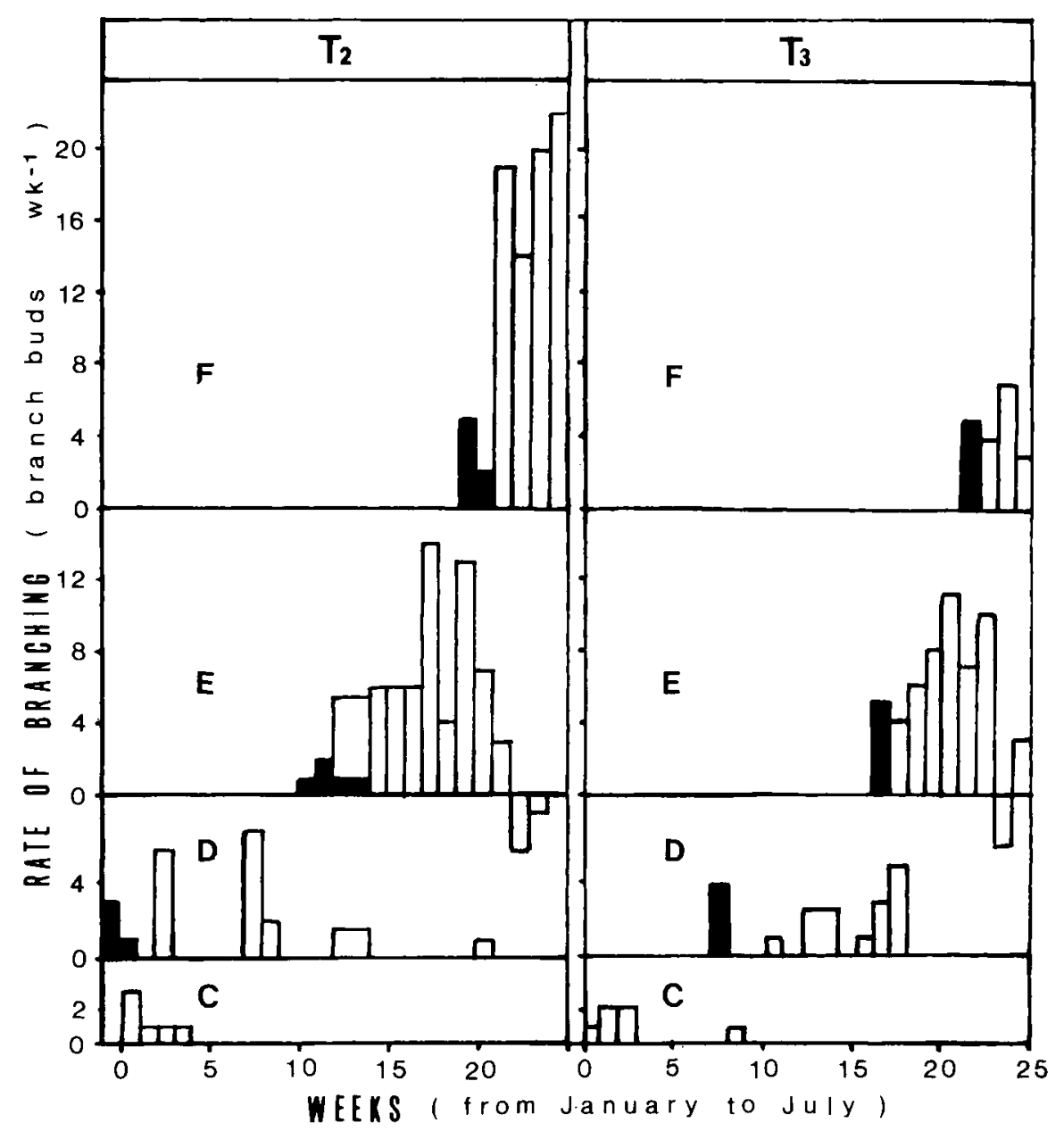

Fig 5. Branching in successive tiers C-F (alphabetical order indicates order of appearance) of 2 young Terminalia superba plants $\left(\mathrm{T}_{2}\right.$ and $\mathrm{T}_{3}$ ). Appearance of branch buds on the main stem (black) and on sympodial units (white).

\section{Growth of a "decapitated" plant}

For an unknown reason, the main apex of tree $T_{4}$ died. During February and after, it behaved differently from that of other trees. Main shoot elongation decreased, but did not stop while leaf emergence ceased for about 2 weeks. One week after leaf re-emergence, a branch tier was initiated, and the next week the main apex looked peculiar. A week later, the main shoot had elongated further, but no more leaves had emerged and at least one young leaf had fallen; the main apex 


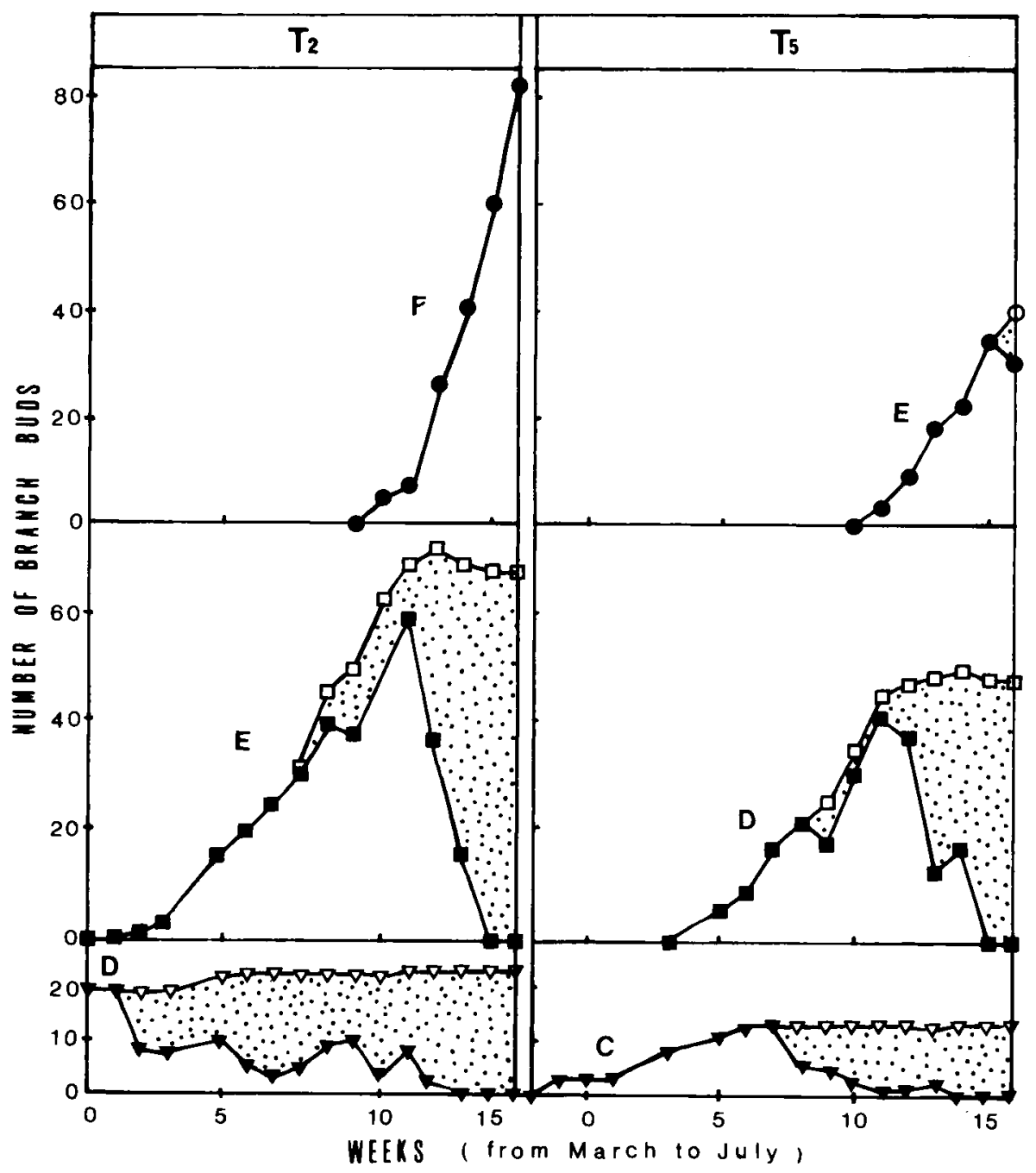

Fig 6. Evolution of number of branch buds in successive tiers (D-F or C-E; alphabetical order indicates order of appearance) of 2 Terminalia superba plants $\left(T_{2}\right.$ and $\left.T_{5}\right)$. These buds are either active or inactive. The difference between the total buds (white symbols) and the active ones (black symbols) represents the inactive buds (dotted area). The number of active buds indicates (apparent) primary activity.

seemed to have been eaten. Finally, the main shoot stopped elongating and lost another young leaf; the main apex looked dead. However, branching was occurring in tiers and the 3 branches that had been initiated just before the main apex died 


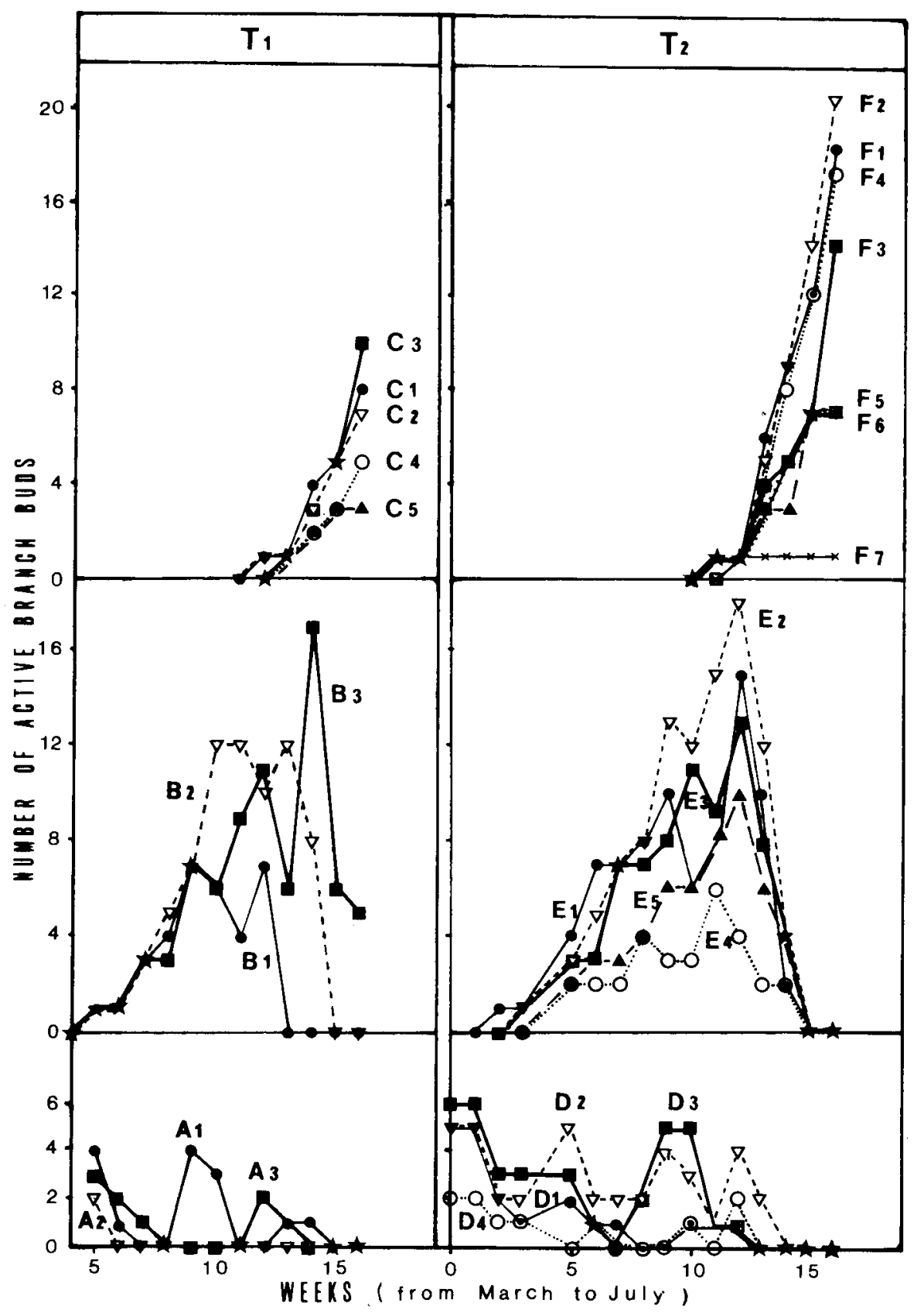

Fig 7. Evolution of number of active branch buds in different branches of successive tiers (A-C or D-F), in 2 young Terminalia superba plants $\left(T_{1}\right.$ and $T_{2}$ ). Subscripts indicate different branches within a tier. 


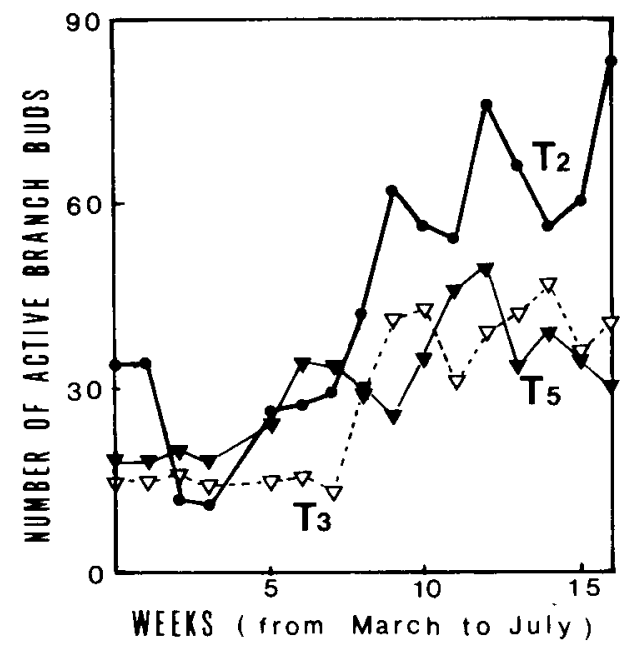

Fig 8. Evolution of total number of active branch buds in 3 young Terminalia superba plants $\left(T_{2}\right.$, $\mathrm{T}_{3}$ and $\mathrm{T}_{5}$ ).

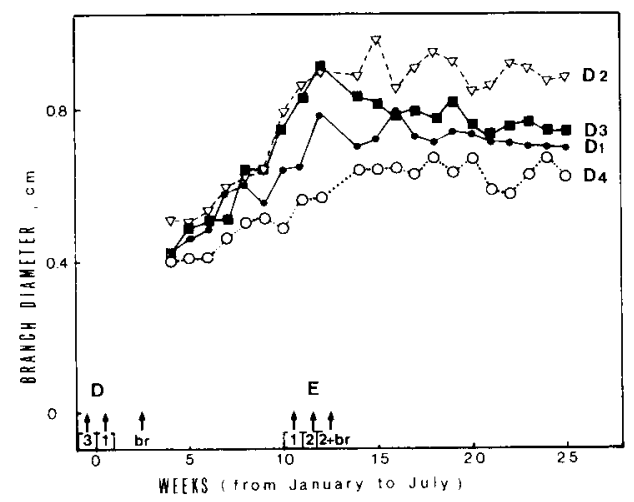

Fig 9. Radial growth of different branches $D_{1}$ $D_{4}$ at the base in tier $D$ of a Terminalia superba plant $\left(T_{2}\right)$. The appearance and number of branch buds are indicated [ $\uparrow$ ], together with the beginning of branching (br) in lateral shoots of both the 2 successive tiers $D$ and $E$.

were developing normally, although at first slowly (fig 12). At least 5 weeks after the main apex died (and while branching was

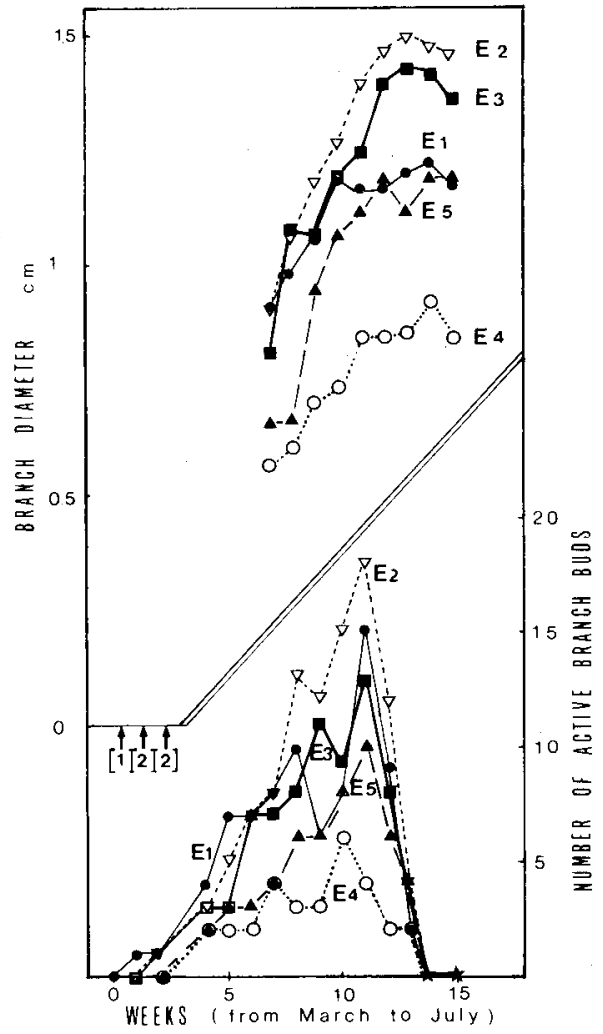

Fig 10. Radial growth of branch base and evolution of number of active branch buds in different branches $E_{1}-E_{5}$ of a tier, in a Terminalia superba plant $\left(T_{2}\right)$. The appearance and number of branch buds generating the 5 branches are indicated $[\uparrow]$.

occurring), the apex of the first sympodial unit was reactivated in the 3 last-formed branches (stage 1). Then, all the other branch buds in the uppermost tier were reactivated simultaneously (stage 2). Two weeks later, the first sympodial unit of each branch in this tier had entered a phase of rapid vertical growth (stage 3). Finally, that of the uppermost branch elongated faster than that of the other 2. A bud expanded sylleptically on the most elongat- 


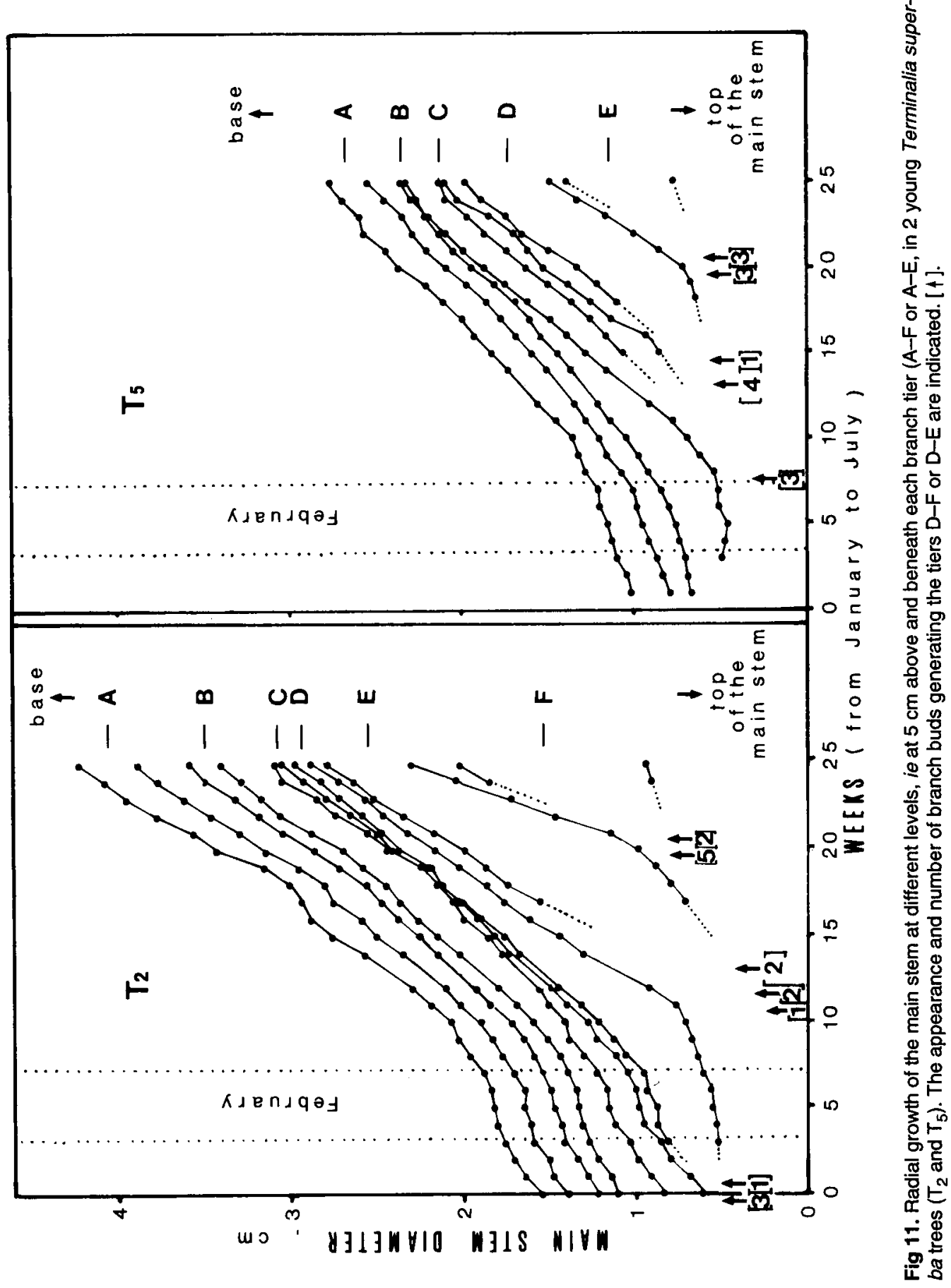




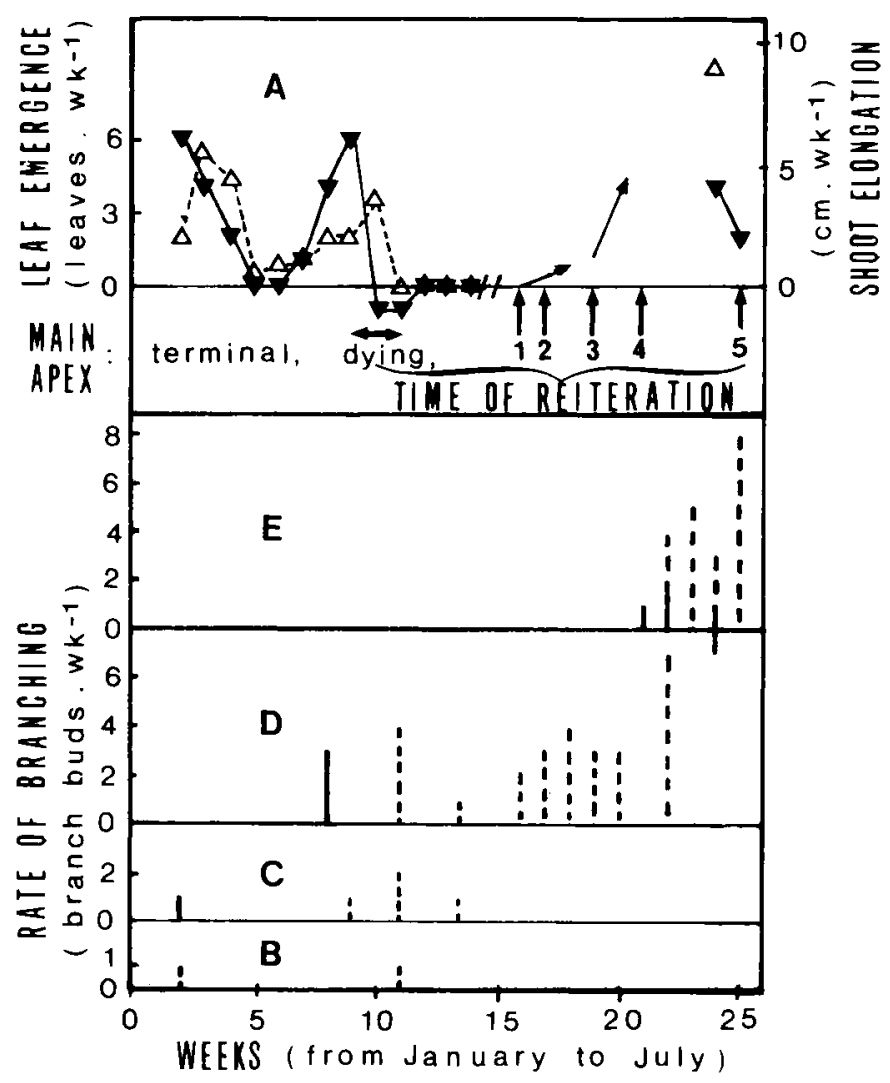

Fig 12. Particular features of development of the individual $T_{4}$, before and after its terminal apex died. $A$ : leaf emergence $(\nabla-\nabla)$, shoot elongation $(\Delta--\Delta)$ and evolution of the main apex from terminal to reiterated (5); stages of reiteration 1-4, see text. B-E: rate of branching in successive tiers (B-E); appearance of branch buds on the main stem ( $\mid$ ) and on sympodial units $\left(\begin{array}{l}1 \\ 1\end{array}\right)$.

ed sympodial unit, at the axil of one of the leaves that were produced during the rapid vertical growth phase, 2 weeks after the growth change was recorded (stage 4). Other buds expanded sylleptically on the same vertical axis during the following 3 weeks and a new tier of branches developed. The first sympodial unit of the lastformed branch (before the main apex died) thus presented the orthotropic growth and branching pattern of the main stem. Then the other 2 sympodial units that were in a rapid vertical growth phase stopped growing quickly, one after another. Finally, apical dominance was re-established and the tree had a new main stem (stage 5).

Radial growth of the 'decapitated' plant was similar to the other plants, except in the young parts of the tree: branches that were recently initiated when the main apex died thickened more rapidly, especially the uppermost branch base when it became 
the main axis (fig 13). Moreover, the part of the main stem that was located above developing tier stopped growing radially, whereas radial growth looked normal below this branch tier.

\section{DISCUSSION}

The species $T$ superba is native to the tropical forests of Africa. It is disseminated throughout the evergreen rain forest, like the forest of Anguédédou, but it invades the secondary bush; it grows very fast in full sun (Aubréville, 1959). $T$ catappa seedlings behave similarly in full sun, whereas seedlings in deep shade may grow for many years with little or no branching (Fisher, 1978). Planting and growing conditions of the trees studied were definitively favourable to the rapid development of the species. Climatic con-

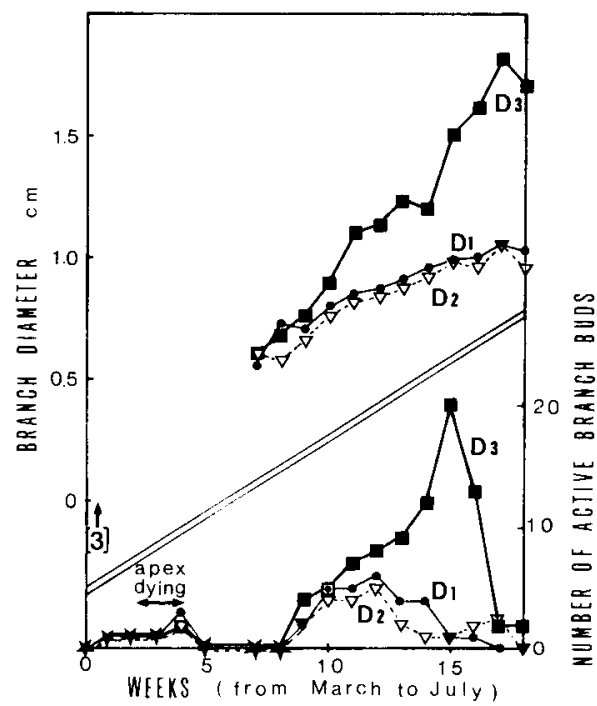

Fig 13. Radial growth of branch bases and number of active branch buds in the tier $D$ of the Terminalia superba plant $\left(\mathrm{T}_{4}\right)$ the main apex of which had just been destroyed. The appearance of the 3 branches $D_{1}-D_{3}$ is indicated [ $\uparrow$ ]. ditions at the site during the wet seasons are also assumed to be particularly favourable for rapid growth of the species because firstly, the rainfall was no longer restrictive and secondly, the mean temperature and the photoperiod were very close to the $27^{\circ} \mathrm{C}$ and $14 \mathrm{~h}$ daylength found to be the most favourable for the development of young $T$ superba plants in a controlled climate chamber (Maillard, 1987; Maillard et al, 1987a).

The results of this examination confirm these data and reveal some interesting points. It is thus concluded that in a favourable natural environment, primary and secondary growth of the main stems of young $T$ superba plants were more continuous than intermittent. There was no rest period, but leaf emergence and shoot elongation fluctuated correlatively. Main shoots displayed a particular growth periodicity. Leaf development was homoblastic without reduced foliage leaves or bud scales. This indistinct periodicity of the main shoot growth had little effect on the tree structure. It has been shown previously (de Faÿ, 1992) that at an early stage in the development of this species, trunks and trunk wood did not exhibit typical units of extension along trunk and rhythmic growth rings in trunk wood.

In short, main shoots of young $T$ superba plants did not flush in a favourable natural environment; their growth-habit was midway between the continuous growth of Carica papaya, an unbranched tropical species (Ng, 1979) and the flushing growth of many tropical woody species such as Camellia thea (Bond, 1942, 1945), Hevea brasiliensis (Hallé and Martin, 1968), Theobroma cacao (Greathouse et al, 1971; Vogel, 1975a, b), and a few temperate ones such as Quercus robur (Payan, 1982; Champagnat et al, 1986). In $T$ superba, the main shoot growth rate fluctuation was similar to that in some tropical and temper- 
ate woody species, such as Persea americana, Pinus taeda, Populus deltoides (Borchert, 1976), Tabernaemontana crassa (Prévost, 1972) and to the radial growth rate in Hevea brasiliensis saplings (de Faÿ, 1986). As Borchert (1973, 1978) claimed, there are only gradual - not basic - differences between flushing and continuous shoot growths.

There are some arguments in favour of the endogenous origin of this indistinct periodicity: i) the existence of periodic variations of main shoot growth in a natural environment under a favourable climate as under controlled environmental conditions (Maillard, 1987); ii) the same region for the mean period of rhythms in a favourable natural environment as at $27^{\circ} \mathrm{C}$ and with a $16 \mathrm{~h}$ daylength (Maillard, 1987); iii) the asynchronism of growth within the individual plants issued from seedlings, during the long rainy season (opposed to the synchronism within the same trees at the end of the long dry season).

Main growing points might have minute leaf primordia that could not be detected during the examination. Leaf emergence was thus observed and leaf initiation was not. In the "decapitated" tree, leaf emergence was arrested during the same week as when the main apex was first observed to be peculiar, which supports the view that leaves emerged rapidly after being initiated.

The time-lag between leaf emergence and shoot elongation rhythms, shown in main axes of young $T$ superba plants, is similar to that between leaf initiation and shoot elongation rhythms during flushes of Quercus robur seedlings grown under constant temperature and illumination (Champagnat et al, 1986; Champagnat, 1989), and Erica $x$ darleyensis grown in vitro (Viemont and Beaujard, 1983). This emphasizes that there is no basic difference between flushing growth, typical of Quercus robur seedlings in a controlled climate chamber and Erica $\mathrm{x}$ darleyensis in vitro, and continuous growth of young $T$ superba plants in a natural tropical environment. Furthermore, the regulatory effect of developing leaves on internode elongation, demonstrated in young $T$ superba plants (Maillard et al, 1987b) may account for the lag of the shoot elongation rhythm behind the leaf emergence rhythm.

As for secondary growth of main stems, neither temporal variations in radial growth rate, examined in this paper, nor spatial variations in wood structure (de Faÿ, 1992) showed evidence of a relation to primary growth of the same axes. Apparently, the change in radial growth rate of the uppermost part of main stems and the structural variations in trunk wood were more related to the periodic occurrence of branches and the dynamics of branching. The influence of the developing branch tier will be discussed below.

In the young plants studied, lateral axes arose during phases of rapid leaf emergence and of rapid elongation of the main shoot, which explains the formation of branch tiers and the acrotonic form of trees. These results are similar to Fisher's data (1978) showing that branch buds start during maximum shoot growth in mature $T$ catappa but according to other authors (Hallé and Oldeman, 1970 writing about $T$ catappa; Maillard, 1987; Maillard et al, 1989 writing about young $T$ superba growing in a controlled glasshouse), branch buds develop when vertical growth is stopped or when the main axis enters low growth phases. The present results agree with the observations of Champagnat (1961, 1965) on sylleptic shoots (called "anticipated" shoots) in Alnus glutinosa: these arise only when the growth rate of main shoots exceeds a certain threshold value and they are confined to vigorous shoots in juvenile trees. This idea was developed by Tomlinson and Gill (1973) who added that, in tropical trees in a nonsea- 


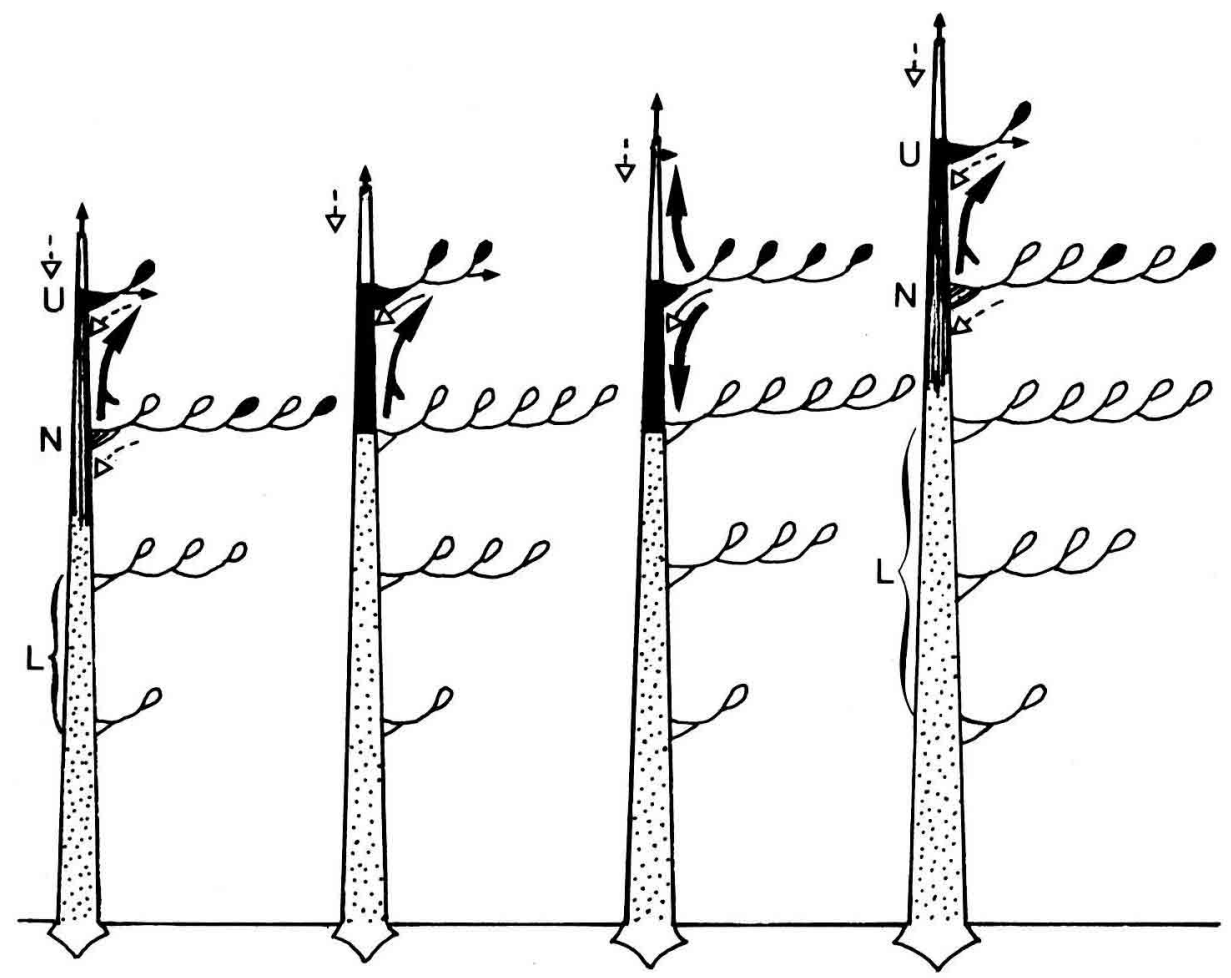

\section{Caption}

It apex more or less active ; -2 active branch bud; D (apparently) inactive branch bud.

- rapid, increasing or decreasing, moderate, 口 slight or no secondary growth.

$U$ uppermost, $N$ next uppermost, L lower tiers. fluxes of photosynthates, other nutrients and growth regulators, such as cytokinins; $\hat{T}$ or $\stackrel{A}{a} \mid A$.

Fig 14. Schematic drawings of the differential growth in the shoot system of young Terminalia superba trees, in relation to the presumed change in the location of sinks and sources of nutrients and growth regulators.

sonal climate, the threshold value may be exceeded periodically, so that several tiers of branches can grow out in one year. In the young $T$ superba plants studied, the "threshold" would be periodically exceeded, which would lead to a maximum activi- 
ty of the main apex and to the appearance of sylleptic outgrowths nearby, on the main shoot in general. These 2 concomitant events (maximum activity of the main apex and the appearance of sylleptic shoots) might be of the same nature. This view may be all the more probable since, according to Champagnat (1989), several biochemical studies in temperate trees show a parallelism between the regrowth of apical buds following the rest in flushing seedlings, and the release of axillary buds from apical dominance (resulting in proleptic shoots), in trees.

All the branches of the $T$ superba plants studied were built up in the same pattern, that is to say by apposition of basic sympodial units, the structure and growth of which, studied by Maillard (1987), are similar to the well-known ones of $T$ catappa (Hallé and Oldeman, 1970; Fisher, 1978): these sympodial units are characterized by a long horizontal basal segment composed of a few leaves and internodes growing rapidly, continued by a slowgrowing vertical segment ending in a rosette of leaves. In one of the trees studied, the accidental death of the main apex just after the initiation of a new tier proved that this main apex contributed to limiting the vertical growth rate of the nearest sympodial units, as in T catappa (Attims in Hallé and Oldeman, 1970), but apparently, it did not control the lateral growth of branches. Indeed, basic sympodial units were not repeated indefinitely in trees, but each branch of the developing tier stopped expanding leaves and growing laterally soon after the occurrence of a new set of lateral axes, above the tier in question. The cessation of radial growth in branches, as well as changes in the radial growth rate of the upper part of main stems were also recorded soon after the occurrence of a new tier. Consequently, the bulk of active branch buds and the maximum growth rate in secondary meristems advanced periodi- cally upwards (as shown diagramatically in fig 14).

These data imply that at first, the developing uppermost tier acted as a recipient sink for water and nutrients and the competition for them was made at the expense of the next uppermost tier and maybe the apex. The shrinkage of some branch bases in the next uppermost tier was an argument in favour of the flux of water towards the recently initiated tier because, firstly, axis shrinkage is assumed to indicate a loss of water and, secondly, the shrinkage of branch bases started at the beginning of branching in the recently initiated tier. The developing tier exhibited more and more branch buds, each of them expanding into a rosette of leaves and remaining active for several weeks. As young leaves of buds are assumed to synthesize plant growth regulators - auxins, cytokinins and abscisic acid were found in developing leaves of main axes in $T$ superba (Maillard, 1987) - and mature leaves are photosynthesizers, the new tier of branches would finally act as a source of photosynthates and probably plant growth regulators for the rest of the shoot system. Once surplus metabolites were produced by the new tier of branches, the main apex would become the recipient sink and the "threshold value of the vigour" would be exceeded in the uppermost young part of the main stem, resulting in the occurrence of new sylleptic axillary shoots. The fact that branching in lateral axes was not dependent on the main apex would explain why the developing tier could temporarily become the current sink of the shoot system. All this leads to the conclusion that the appearance of new lateral shoots on main stems depended on the growth of the preceding tier, at least partially.

Other arguments support this view. Firstly, since a new tier of branches did not always occur at each point of maximum emergence of main shoot leaves and since 
leaf emergence was apparently close to leaf initiation, tier initiation should not only depend on the maximum activity of the main apex. Secondly, the instance of the one "decapitated" plant supports this point of view. Because growth of the branch tier, which was initiated just before the main apex died, seemed to be a prerequisite for both the reiteration of the main stem and the appearance of another branch tier, and also because the initiation of the lastformed tier preceded the reiteration of the leading apex, it is difficult to believe that the release of young axillary buds from apical dominance was an essential and sufficient requirement for a tier initiation. Of course, no other examples nor any plants decapitated during another stage of the tier growth were observed. Moreover, the leader reiteration in the $T$ catappa tree experimented by Attims (in Hallé and Oldeman, 1970) was immediate and precocious compared that of the present example where the reiteration of a leading orthotropic axis took 14 weeks. However, the leading shoot, in $T$ ivorensis seedlings, was found to grow faster if the branches were taken off (Damptey and Longman, 1965). Unlike the former example, the latter agrees with the particular growth-habit of young $T$ superba plants. Some experimental decapitation of main and lateral axes of $T$ superba - and other related species - would be very interesting to support the view of the regulatory role played by particular branches on the shoot system development. Without any other data on this subject, but in view of the number of branches the growth of which was followed per tree studied, it is advisable to state that the presumably successive sink source roles of the uppermost tier of branches for metabolites apply only to $T$ superba plants in the early stage and in a favourable natural environment.

The differential radial growth of the "decapitated" main stem also indicated that the main apex was essential only for secondary growth of the uppermost young part of this axis. Therefore, active buds of a growing branch probably exerted a control of hormonal origin (IAA) over cambial growth of the branch in question (see the form of branch base sections), but also over the lower part of the main stem of trees.

Although this work does not permit one to examine the possible effects of circulating cytokinins on the growth out of main stem axillary buds, it seems likely that correlative signals originating from active branch buds, both of nutritional and hormonal origin, play an important role in regulating the development of the shoot system of young $T$ superba trees, as schematized in figure 14.

The influence of seasons (the long dry and the long rainy seasons) on the development of the young $T$ superba plants growing in a natural environment still remains to be examined. A comparative study of the growth rates before and after the month of March has shown that primary and secondary growths, including lateral growth, were optimal throughout the long rainy season, whereas before, ie at the end of the long dry season, growth was restricted: lateral growth stopped generally for longer than terminal growth, and terminal growth slowed down more markedly than radial growth (except for the tree with the apex that subsequently died). Thus it appears that the construction of a vigorous main stem was a priority in the first stage of the development of $T$ superba.

Study of the temporal organization in both primary and secondary, terminal and lateral growth phenomena in the shoot system of the species $T$ superba at an early stage allowed the author to present a dynamic model of growth where main stembranch correlations are basic. Although nothing is known about the root system of 
this species, one must consider that there might be root-shoot interactions, as in peach trees where the root tip and its production of cytokinins are proven to exert considerable control over top growth (Richard and Rowe, 1977a, b). The author wonders whether root restriction could explain why slow shoot growth phases changed into momentary rest periods when the young $T$ superba plants studied by Maillard (1987) had grown for 7 months in a controlled glasshouse.

\section{ACKNOWLEDGMENTS}

The author is grateful to the late Director of the Centre Technique Forestier Tropical of the Ivory Coast, $\mathrm{K}$ Diabate and his colleagues for providing plant material, and JM Favre (University of Nancy 1) for his critical reading of the manuscript.

\section{REFERENCES}

Aubréville A (1959) La Flore Forestière de la Côte d'voire, Vol 3. Centre Tech For Trop, Nogent sur Marne, France

Bond TET (1942) Studies in the vegetative growth and anatomy of the tea plant (Camellia thea Link) with special reference to the phloem. I. The flush shoot. Ann Bot 6, 607-629

Bond TET (1945) Studies in the vegetative growth and anatomy of the tea plant (Camellia thea Link) with special reference to the phloem. II. Further analysis of the flushing behaviour. Ann Bot 9, 183-216

Borchert R (1976) Computer aided evaluation of shoot growth patterns in trees. Univ Kansas Sci Bull 51, 129-14

Borchert R (1978) Feedback control and age related changes of shoot growth in seasonal and nonseasonal climates. In: Tropical Trees as Living Systems (Tomlinson PB, Zimmermann $\mathrm{MH}$, eds) Cambridge Univ Press, 497515

Champagnat P (1961) Dominance apicale. Tropismes, épinastie. In: Encyl Plant Physiol. Springer-Verlag, Berlin, vol 14, 872-908
Champagnat $P$ (1965) Physiologie de la croissance et de l'inhibition des bourgeons : dominance apicale et phénomènes analogues. Rameaux courts et rameaux longs. Problèmes physiologiques. In: Encyl Plant Physiol (Ruhland W, ed) Springer-Verlag, Berlin (vol 15/1), 1106-1171

Champagnat $P$, Payan $E$, Champagnat $M$, Barnola P, Lavarenne S, Bertholon C (1986) La croissance rythmique de jeunes chênes pédonculés cultivés en conditions contrôlées et uniformes. Coll Int l'Arbre. Nat Monspeliensia 303-337

Champagnat $P(1989)$ Rest and activity in vegetative buds of tiers. Ann Sci For 46 suppl; Forest Tree Physiology (Dreyer E et al, eds) Elsevier/INRA, 9s-26s

Damptey HB, Longman KA (1965) Main stem and branch growth in Terminalia ivorensis $A$ Chev. J W Afr Sci Assoc 10, 69

Faÿ E de (1986) Mode de croissance cambiale de quelques arbres tropicaux au stade juvénile. Coll int Arbre Nat Monspeliensia. 13-27

Faÿ E de (1992) Vegetative development, primary and secondary growth of the shoot system in young Terminalia superba tropical trees, in a natural environment. I. Spatial variation in structure and size of axes. Ann Sci For 49, 389-402

Fisher JB (1978) A quantitative study of Terminalia branching. In: Tropical Trees as Living Systems (Tomlinson PB, Zimmerman, $\mathrm{MH}$, eds), Cambridge Univ Press, 285-320

Greathouse DC, Laetsch WM, Phinney BO (1971) The shoot-growth inythm of a tropical tree, Theobroma cacao. Am J Bot 58, 281-286

Hallé F, Martin R (1968) Étude de la croissance rythmique chez l'hévéa (Hevea brasiliensis Müll-Arg Euphorbiacées-Crotonoidées). Adansonia 2 (8), 475-503

Hallé F, Oldeman RAA (1970) Essai sur l'architecture et la dynamique de croissance des arbres tropicaux. Monogr Bot et Biol Vég. Masson, Paris

Maillard $P$ (1987) Étude du développement végétatif du Terminalia superba Englers et Diels en conditions contrôlées : mise en évidence de rythmes de croissance. Thesis, Univ, Paris VI, France

Maillard $P$, Jacques $M$, Miginiac $E$, Jacques $R$ (1987a) Croissance de jeunes Terminalia su- 
perba Englers et Diels en conditions contrôlées. Ann Sci For 44, 67-83

Maillard P, Jacques M, Miginiac E (1987b) Correlative growth in young Terminalia superba in a controlled environment: effect of the leaves on intemode elongation. Ann Sci For 60, 447-454

Maillard $P$, Jacques $M$, Miginiac $E$, Millet $B$ (1989) Mathematical analysis and comparison of growth fluctuations of the aerial system of young Terminalia superba Englers et Diels (Combretaceae). Ann Sci For 46 suppl; Forest Tree Physiology (Dreyer E et al, eds) Elsevier, INRA, 202s-205s

Ng FSP (1979) Growth rhythms in tropical juvenile trees. Bull Soc Bot Fr 126, Actual Bot 139-149

Payan E (1982) Contribution à l'étude de la croissance rythmique chez les jeunes chênes pédonculés (Quercus pedonculata EhM). Thesis, Univ Clermont-Ferrand, France

Prévost MF (1972) Rythme d'allongement des articles de Tabernaemontana crassa Benth (Apocynacées). Candollea 27, 219-227
Richard D, Rowe RN (1977a) Effects of root restriction, root pruning and 6-benzylaminopurine on the growth of peach seedlings. Ann Bot 41, 729-740

Richard D, Rowe RN (1977b) Root-shoot interactions in peach: the function of the root. Ann Bot 41, 1211-1216

Tomlinson PB, Gill AM (1973) Growth habits of tropical trees: some guiding principles. In: Tropical Ecosystems in Africa and South America: A Comparative Review (Meggers BJ, Ayensu ES, Duckworth WD, eds) Smithsonian Inst Press, Washington, DC, 129-143

Viemont JD, Beaujard $F$ (1983) Les bruyères in vitro: II. Élongation et organogenèse lors de la croissance rythmique chez Erica $x$ darleyensis. Bull Soc Bot Fr 130; Lett Bot 317324

Vogel M (1975a) Croissance rythmique du cacaoyer. Thesis, Univ Paris XI, Orsay

Vogel M (1975b) Recherche du déterminisme du rythme de croissance du cacaoyer. Café Cacao The 19, 265-290 